\title{
Response to Tocilizumab Treatment in Severe COVID-19
}

Emma H Baker ${ }^{1,2^{*}}$, Kamal Patel ${ }^{3^{*}}$, Jonathan Ball ${ }^{4}$, Sarah Edwards ${ }^{5}$, Thomas S Harrison ${ }^{1,6}$, Arvind Kaul7, Mickey Koh ${ }^{8}$, Sanjeev Krishna ${ }^{1,6,9,10}$, Vinodh Kumar ${ }^{2}$, Susannah Leaver ${ }^{4}$, Daniel Forton ${ }^{1,3}$

1. Institute of Infection and Immunity, St. George's University of London, UK

2. Pharmacy and Medicines Directorate, St George's University Hospitals NHS Foundation Trust, London, UK

3. Department of Gastroenterology and Hepatology, St George's University Hospitals NHS Foundation Trust, London, UK

4. Adult Critical Care Directorate, St George's University Hospitals NHS Foundation Trust, London, UK

5. Department of Science and Technology Studies, University College London, UK

6. Clinical Infection Unit, St George's University Hospitals NHS Foundation Trust, London, UK

7. Department of Rheumatology, St George's University Hospitals NHS Foundation Trust, London, UK

8. Department of Haematology, St George's University Hospitals NHS Foundation Trust, London, UK

9. Institut für Tropenmedizin, Universitätsklinikum Tübingen, Tübingen, Germany

10. Centre de Recherches Médicales de Lambaréné, Gabon

* Joint first authors

Corresponding authors

Daniel Forton, Department of Gastroenterology and Hepatology, St George's University Hospitals NHS Foundation Trust, London, UK, Daniel.forton@nhs.net, Tel: +44 2087253750

Sanjeev Krishna, Institute of Infection and Immunity, St. George's University of London, UK, sgjf100@sgul.ac.uk 


\section{Abstract}

Background: Since the COVID-19 pandemic began in December 2019 no specific therapy for managing severe complications of infection has emerged, although this is under intensive investigation. Progressive pneumonia and multi-organ complications are managed with supportive care and COVID-19 has a mortality of $>50 \%$ when ventilatory support is needed.

Methods: We implemented a compassionate use protocol for tocilizumab, a humanised monoclonal anti-II-6 receptor antibody. Patients with severe COVID-19 requiring oxygen or ventilation, and complicated by hyperinflammation and the cytokine release syndrome (CRS) received tocilizumab (8 $\mathrm{mg} / \mathrm{kg}$ up to a maximum of $800 \mathrm{mg}$, with the option of a second dose given after 12-24 hours). CRS was defined as having at least three of: D-dimer above the upper limit of normal (ULN), rising Creactive protein (CRP), ferritin $>1000 \mathrm{ng} / \mathrm{mL}$ and lactate dehydrogenase (LDH) greater than the ULN.

Oral consent for prescription of an off-label medicine was obtained from patients, their next of kin or representative, whenever possible. The treatment protocol adhered to the Monitored Emergency Use of Unregistered and Investigational Interventions of the WHO.

Findings: Of seventeen patients with severe COVID-19 seen between 3-12th April 2020, eleven patients (seven ventilated and four receiving high flow oxygen) were treated with tocilizumab. Treatment normalised temperatures within 48 hours and was associated with a significant fall in CRP from 311 (138-332) (median, IQR mg/L) to $110(58-184)(p=0.001)$. For the group, oxygen requirements fell by $60 \pm 32 \%(95 \% \mathrm{Cl} 38-81)$ over 1 week $(p<0 \cdot 001)$. Two of seven patients on intensive care died, five have been extubated and two discharged. All four ward patients have also been discharged.

Interpretation: Following tocilizumab treatment, we observed improvement in clinical and laboratory abnormalities in this small series. Compassionate use of tocilizumab can provide valuable information to support clinical trials in patients with severe COVID-19.

Funding: None specific. 


\section{Introduction}

In early December 2019, a novel enveloped RNA betacoronavirus was recognised as the cause of an outbreak of pneumonia cases in Wuhan, China. The virus now designated severe acute respiratory syndrome coronavirus 2 (SARS-CoV-2), is phylogenetically similar to SARS-CoV which caused a global outbreak of SARS in 2003. On March $12^{\text {th }}, 2020$, the World Health Organisation announced the SARSCoV-2 outbreak as a pandemic and as of April $22^{\text {nd }}$, there have been $2,585,520$ cases and 179,881 deaths as a consequence of the clinical manifestation, termed COVID-19. The overall case fatality rate is estimated at $3-4 \%{ }^{1}$ but in severe COVID-19, it has been reported to be greater, as high as $80 \%$, especially when associated with a requirement for mechanical ventilation. ${ }^{2-4}$

The emerging evidence suggests that hyperinflammation, due to the host immune response and leading to a cytokine storm, may promote disease severity in SARS-CoV-2 infection. A multicentre study of 150 confirmed COVID-19 cases in Wuhan, China demonstrated that a lower lymphocyte count and an elevated C-reactive protein (CRP) were associated with the primary endpoint of ICU admission, mechanical ventilation or death. ${ }^{5}$ Factors associated with fatality included age, presence of underlying disease, secondary infection and elevated inflammatory markers such as ferritin and serum IL-6. Similar predictors were noted in a second retrospective cohort study from Wuhan, China. ${ }^{6}$ Multivariable regression showed increasing odds of in-hospital death associated with older age, higher Sequential Organ Failure Assessment score and D-dimer values greater than $1000 \mathrm{ng} / \mathrm{mL}$ on admission.

Cytokine Release Syndrome (CRS) is a form of Systemic Inflammatory Response Syndrome (SIRS) characterised by fever, systemic inflammation indicated by high CRP and hyperferritinaemia, multiorgan failure, and high mortality. Many of these features are seen in severe COVID-19, 7,8 where there appears to be a unique pattern of hyperinflammatory responses and immune dysregulation, driven by over-production of pro-inflammatory cytokines by monocytes. ${ }^{9}$ In particular, very high levels of IL-6 production are associated with low HLA-DR expression and profound lymphopenia.

Importantly, CRS is a complication of Chimeric Antigen Receptor T (CAR-T) cell therapy for refractory B cell leukaemias and lymphomas, a situation where IL- 6 antagonism with tocilizumab is clinically effective. Tocilizumab is a humanised anti-IL-6 receptor antibody that is licensed for CRS treatment in this context, ${ }^{10,11}$ in addition to the long established indications for treatment of Rheumatoid Arthritis, Juvenile Idiopathic Arthritis, Giant Cell Arteritis and Large Vessel Vasculitis. ${ }^{12}$ Rapid clinical improvement in several patient CRS cohorts including symptom resolution after a single dose led to FDA approval in 2017. ${ }^{11}$ Early introduction of anti-IL-6 in the setting of CRS is considered vital. While 
possibly appearing counter-intuitive in the face of severe viral infection, a similar immunosuppressing approach might yield benefit in severe COVID-19. A report of tocilizumab treatment in one patient with a background history of myeloma noted clinical resolution of COVID19 pneumonia and confirmation of significant radiological improvement. ${ }^{13}$ Findings from a case series of 15 patients who were treated with tocilizumab, combined with methylprednisolone in nine cases, suggested that it might have utility to prevent or treat the cytokine storm induced by COVID19. ${ }^{14}$ Stabilisation of symptoms was reported in nine patients, who were all moderately or seriously ill after seven days, although definitions of illness severity were not given. The four critically ill patients either died or deteriorated in this case series, and according to the authors, might have benefited from a second dose. A second uncontrolled series from China reported outcomes of 21 patients with severe COVID-19 pneumonia who were treated with tocilizumab and demonstrated clinical benefit, with normalisation of CRS parameters and improvements in radiological findings. ${ }^{15}$ 19 patients (91\%) had been discharged from hospital at time of pre-publication whilst the other two patients continued to show clinical improvement. A consistent feature of these early reports is a reduction in the CRP, a likely direct consequence of IL-6 blockade and early improvement in respiratory parameters in some patients.

Given that first, there is no licensed therapy for severe COVID-19 that has been proven in clinical trials, second, mortality in severe SARS-CoV-2 infection has been reported to be greater than $50 \%$, especially when associated with hyperinflammation or the need for mechanical ventilation, ${ }^{2-4}$ and third, a surge in severe COVID-19 hospitalisations was predicted, we considered the compassionate use of tocilizumab in selected patients. Compassionate use is a treatment option for prescription of an unlicensed medicine for patients who have a disease with no satisfactory therapy and for whom there are no current clinical trials. Compassionate use recognises that clinical trials may take time to set up and may not report in time to save patients who may die before results are published. In the context of the current SARS-CoV-2 pandemic, the World Health Organisation (WHO) states that it can be ethically appropriate to offer individual patients experimental interventions on an emergency basis outside clinical trials, provided that no proven effective treatment exists; it is not possible to initiate clinical studies immediately; the patient or his or her legal representative has given informed consent; and the emergency use of the intervention is monitored, and the results are documented and shared in a timely manner with the wider medical and scientific community. ${ }^{16}$

We used these principles to guide our use of tocilizumab in patients with severe COVID-19 disease, whilst it was unavailable as a clinical trials option in our hospital. Whilst a vaccine and effective therapeutic options are being tested in clinical trials, there is an urgent need to help those patients 
who would otherwise be at grave risk of death using options which are currently available and effective in similar situations. We established clinical criteria for treatment of symptoms that, on the basis of the current literature and multidisciplinary discussion, were predicted to offer the best outcomes.

\section{Method}

A multidisciplinary committee was convened with relevant expertise (intensive care, infectious disease, haematology, clinical pharmacology, biologicals, rheumatology) to agree criteria to guide clinicians who were considering compassionate use of tocilizumab. Ethical review of these criteria and the mechanisms to implement them was through an ethicist experienced in advising the WHO on outbreaks (SE). Off-label treatment with tocilizumab was discussed with patients when possible and oral consent was obtained from patients, relatives or professionals as appropriate and recorded in patients' records. It was prescribed on a named patient basis. The need for written informed consent specifically for tocilizumab was not considered necessary. The treatment protocol to guide clinician decision making is outlined in a supplementary document.

Patients

All patients with COVID-19 were recommended to have daily testing of markers of hyperinflammation at St George's Hospital, Tooting from 3rd April (CRP, ferritin, LDH and D-dimer). For consideration to receive tocilizumab patients required a confirmed diagnosis of SARS-COV-2 by polymerase chain reaction or, in the case of rapid clinical deterioration, a strong clinical suspicion of severe COVID-19, based on consistent clinical and radiological features. In addition, a chest x-ray or CT chest confirming bilateral infiltrates was required for all patients.

Patients were further divided into two groups: those that had been intubated and ventilated within the last 24 hours for COVID-19 (extended to 48 hours for external referrals transferred directly into the intensive care unit); and ward-based patients who had a fever $\left(>37.8{ }^{\circ} \mathrm{C}\right)$ and inspired oxygen requirements of $\geq 28 \%$. In addition to the above criteria, all patients were required to have evidence of a hyper-inflammatory phenotype with at least three of the following: D-dimer above the upper limit of normal, rising CRP, ferritin $>1000 \mathrm{ng} / \mathrm{mL}$ and lactate dehydrogenase (LDH) greater than the upper limit of normal. Patients were not considered for treatment if the following criteria applied: alanine aminotransferase (ALT) or aspartate aminotransferase (AST) greater than ten times the upper limit of normal, neutrophils $<0.5 \times 10^{9} / \mathrm{L}$, platelets $<50 \times 10^{9} / \mathrm{L}$, a risk of intestinal perforation 
(e.g. history of diverticulosis), hypersensitivity to tocilizumab, evidence of multi-organ failure, bacterial sepsis, intubation for reasons other than COVID-19, a clinical frailty score of $>6$ or a Charlson co-morbidity index $>6.17,18$

Patients, who in the view of their physicians were considered eligible to receive tocilizumab, were discussed by the multidisciplinary panel, who operated virtually and who were provided with clinical and laboratory details on a summary information sheet. After any clarifications and requests for further details were addressed, a consensus decision was obtained for all patients and documented in the clinical record.

When a patient was able to converse and was mentally competent, s/he was offered a full explanation of potential benefits and potential risk (lack of benefit or a small but unquantified risk of adverse events). When a patient was unable to give consent, where possible, the treatment was discussed with the patient's nominated attorney where there was one or the next of kin to help determine best interests. For all patients, an oral professional consent was required from the treating physician. In patients receiving tocilizumab, hepatitis B serology (HBV core antibody, surface $\mathrm{Ag}$ ) was sent but results were not required prior to commencing treatment. The administration of tocilizumab did not alter the standard of care supportive therapy. Additional treatments necessary or already in place were not altered.

\section{Dosing}

The administered dose was $8 \mathrm{mg} / \mathrm{kg}$ intravenous tocilizumab up to a maximum of $800 \mathrm{mg}$ (the dosage approved by the FDA for the treatment of the cytokine storm following treatment with CAR-T cells). A second same dose was administered after 12-24 hours if respiratory function was not improving or deteriorating, at the discretion of the treating physician, advised by the expert panel.

\section{Safety and efficacy assessments}

We prospectively collected information relating to vital signs, incidence of key clinical events (such as bacterial sepsis or death), changes in standard blood tests and inflammatory parameters and oxygen-support requirements.

The proportion of patients with clinical improvement was evaluated utilising the ordinal scale for clinical improvement (as recommended by the WHO R\&D Blueprint expert group. ${ }^{19}$ The 8-point scale consists of the following categories: 0 , Uninfected, no clinical evidence of infection; 1 , Ambulatory, 
no limitation of activities; 2, Ambulatory, limitation of activities; 3, Hospitalised, no oxygen therapy; 4, Hospitalised requiring oxygen by mask or nasal prongs; 5, Hospitalised requiring non-invasive ventilation or high flow oxygen; 6, Hospitalised requiring mechanical ventilation; 7, Hospitalised requiring ventilation and additional organ support (pressors, renal replacement therapy); 8 , Death. For the purpose of analysis, patients were considered to have improved if their score on the WHO ordinal scale had fallen at least one point from the day of tocilizumab dosing on the latest day of follow up. Changes in oxygen-support requirements were reported as either a reduction in inspired oxygen requirements (as a change in oxygen flow rates for non-intubated patients) or a change in the $\mathrm{PaO}_{2}(\mathrm{kPa})$ to $\mathrm{FiO}_{2}(\%)$ ratio for ventilated patients.

\section{Statistical analysis}

As this was a series of patients treated on a named patient basis on compassionate grounds, no $a$ priori statistical analyses were planned. Continuous variables are reported as mean \pm standard deviation with range (minimum to maximum) or median (interquartile range) as relevant. Change in inflammatory markers and haematological parameters are reported as percentage change from baseline using mean [95\% confidence intervals]. Values for two related variables were compared using paired t tests; more than two related variables were compared using the Friedman test; and variables in unrelated groups were compared using Mann-Whitney U tests. IBM SPSS V26.0 was used for analysis. The analysis includes all patients who have received tocilizumab. The first patient received tocilizumab on the 3rd April, and data are reported from the 3rd April to time of writing (22nd April).

\section{Results}

Patients

Seventeen patients with SARS-CoV-2 pneumonia were considered for treatment with tocilizumab and eleven were selected by the panel as they fulfilled the criteria that had been set. Seven were intubated and ventilated on intensive care and four were receiving high flow oxygen via a face mask on medical wards. Their characteristics are shown in table 1. All patients had hyperinflammation and were considered by their attending clinicians to have a poor prognosis and no other treatment options. 
All patients received tocilizumab at a dose of $654 \pm 96 \mathrm{mg}$ on at least one occasion, with four intensive care patients receiving a second dose because of judgement by their clinicians that they had had an incomplete response.

Effect of tocilizumab on inflammation

Maximum temperature was $38.0 \pm 0.9^{\circ} \mathrm{C}$ on the day leading up to tocilizumab treatment and fell to $37.2 \pm 0.6^{\circ} \mathrm{C}$ and $37 \cdot 1 \pm 0.3^{\circ} \mathrm{C}$ respectively on the first and second days after treatment $(p=0.009$ (Friedman test)). Daily maximum temperatures for individual patients before and during the 7 days after dosing are shown in figure $1 \mathrm{~A}$.

Plasma C-reactive protein was 311 (138-332) $\mathrm{mg} / \mathrm{L}$ on the day leading up to tocilizumab treatment and fell to 218 (151-332) mg/L and 110 (58-184) mg/L respectively on the first and second days after treatment $(p=0.001$ (Friedman test)). Daily C-reactive protein values for individual patients before and for 7 days after dosing are shown in figure 1B.

Table 2 shows percentage changes in inflammatory markers from pre-treatment values by days 1, 2, 3 and 1 week after tocilizumab. C-reactive protein, which has an elimination half-life in blood of around 19 hours, ${ }^{20}$ approximately halved between days 1 and 2 and again between days 2 and 3, as would have been expected if inflammation had been switched off. By day 7, CRP was normal in all but 2 patients, both of whom were being treated for a secondary bacterial infection. Ferritin, which has a plasma elimination half-life of approximately 72 hours, ${ }^{21}$ showed a slower fall than CRP, but was significantly reduced at $44 \%$ baseline by 1 week post dose. LDH levels were unresponsive to tocilizumab treatment and D-dimers increased.

\section{Clinical outcomes}

\section{Efficacy}

Oxygen requirements for patients on the day of tocilizumab treatment and one week later are shown in figure 2. For intensive care patients, $\mathrm{PaO}_{2}: \mathrm{FiO}_{2}$ ratios improved by $11 \pm 8$ [ $95 \%$ confidence intervals ( $\mathrm{Cl})-18$ to -3 ] over 1 week, $\mathrm{p}=0 \cdot 012$. For ward patients, oxygen flow rates were reduced by $8 \pm 2 \mathrm{~L} / \mathrm{min}[95 \% \mathrm{Cl} 5-11]$ over 1 week, $\mathrm{p}=0 \cdot 004$. For the whole group, oxygen requirements measured by either method fell by $60 \pm 32 \%[95 \% \mathrm{Cl} 38-81]$ over 1 week, $\mathrm{p}<0 \cdot 001$. 
The clinical course of patients from the day of first tocilizumab dose to discharge, death or latest progress in hospital at the time of reporting is shown in figure 3. Of the seven patients on intensive care, two died on days 11 and 15 after dosing. The other five have been extubated, with three being discharged from ICU, of whom two have been discharged from hospital. The four ward patients were discharged home on days 7, 10, 11 and 15. Table 3 compares pre-dosing characteristics between patients who had improved by at least one point on the WHO ordinal scale by the latest point of follow up (improvers) and the two patients who did not improve and subsequently died (nonimprovers). Non-improvers had higher LDH, D-dimers, lymphocyte count and lymphocyte*neutrophil product at the time of dosing.

\section{Safety}

Four patients required a new prescription for antibiotics after tocilizumab treatment, at three, five, six and ten days post-dosing respectively. Three of these had positive bacterial cultures (two had Klebsiella aerogenes in sputum, a third had Klebsiella pneumoniae bacteraemia). All of these patients had received a second dose of tocilizumab. Prior to tocilizumab dosing, the four patients who required new antibiotics had a higher lymphocyte count (mean difference $0.5 \times 10^{9} / \mathrm{L}$ [ $95 \%$ confidence intervals $(\mathrm{Cl}) 0.1$ to 0.9$]$ ) and lymphocyte*neutrophil product (mean difference $5.5[95 \% \mathrm{Cl} 0.3$ to 10.7]) than the seven patients who did not require new antibiotics.

Immediately prior to reporting, two patients requiring additional antibiotics had died and two had improved and were extubated. The two deaths were related to multiorgan failure and ventilator associated pneumonia (Klebsiella aerogenes in sputum) and refractory respiratory failure.

\section{Discussion}

Tocilizumab use was associated with a significant and rapid reduction in fever and CRP in all patients. Given the known half-life of CRP in serum of 19 hours, the time course of the reduction in CRP suggests an almost complete shutdown of IL-6 driven CRP production. More importantly, this reduction in fever and CRP was associated with a consistent and progressive improvement in oxygenation over the first week following treatment, suggesting clinically significant effects in reducing lung inflammation. None of four ward-based patients with severe COVID-19 required ventilation, despite poor and deteriorating clinical status prior to tocilizumab therapy and all improved to the point they were discharged; five of the seven ICU-based patients were extubated within a period of 8 to 14 days after treatment. 
We selected patients on the basis of severely deteriorating respiratory function and a panel of markers suggesting a cytokine release syndrome. Our findings are consistent with the proposed pathophysiological role for CRS in severe COVID-19, and with a benefit from the blockade of IL-6 signalling. The results are also consistent with the early reports from China ${ }^{14,15}$ and recent experience in France. ${ }^{22}$

Four of our patients developed evidence of secondary bacterial infection requiring antibiotics (Klebsiella spp. in sputum or blood cultures in three cases). These patients had all received a second dose of tocilizumab, due to an early slow respiratory response. It is not possible to know whether infection was made more likely by tocilizumab, and if the infections were already present at the time of treatment or not. The higher lymphocyte*neutrophil product in patients requiring antibiotics perhaps hints that their pre-treatment morbidity was not exclusively attributable to COVID-19. Exclusion of bacterial infection is difficult, even with more specific markers such as procalcitonin, and careful monitoring and prompt initiation of antibiotics if indicated, guided by the local epidemiology of bacterial infections must be important whether or not tocilizumab is used. Of note, patients diagnosed with post-tocilizumab bacterial infection generally showed a rise in neutrophil count, and one a rise in CRP, despite IL6 blockade. In rheumatoid arthritis and steady state tocilizumab dosing, severe infection (usually all bacterial), can cause the CRP to rise above $200 .{ }^{23}$ It is possible therefore that this patient's rise was a consequence of bacterial infection inducing non-IL-6 inflammatory pathways to release CRP. Data from the BSRBR registry indicate that bacterial infection may be more common with tocilizumab than other injected biologics, although this is in the context of long-term use. ${ }^{24}$ Alternatively, we cannot exclude the possibility that blood concentrations of tocilizumab fell to a level (less than $1 \mathrm{microg} / \mathrm{ml}$ in rheumatoid arthritis ${ }^{25}$ ) that allowed CRP regeneration. It is interesting to speculate whether measurement of tocilizumab levels and/or free IL- 6 might be useful to guide therapy in these patients.

The pattern of hyperinflammation and CRS in this cohort of COVID-19 patients and that seen post CAR-T have common clinical features of IL-6 driven fevers, elevated CRPs and respiratory compromise. They are similarly accompanied by laboratory abnormalities consistent with hemophagocytic lymphohistiocytosis $(\mathrm{HLH})$ or the macrophage activation syndrome (MAS) characterised by hyperferritinaemia and elevated LDH. However, pancytopaenia, including neutropaenias which are a common feature of CRS and HLH post CAR-T is not a feature in this cohort. There is noticeable sustained elevation of D-dimers and a normal or high fibrinogen with preservation of platelet counts. This contrasts with the disseminated intravascular coagulation seen 
in CAR-T associated severe CRS treated with tocilizumab where the laboratory hallmarks are elevated D-dimers, thrombocytopaenia and hypofibrinogenaemia. ${ }^{26}$

It is still not understood why some patients with COVID-19 develop severe disease, characterised by hyper-inflammatory responses and immune dysregulation. It seems likely that genetic influences will be important, as suggested but not yet determined (e.g. status of familial Mediterranean fever or angiotensin converting enzyme gene polymorphisms $s^{27,28}$ ). In this series, there appeared to be an initial favourable response in all patients but two ventilated patients subsequently deteriorated, likely as a consequence of bacterial infection. The predictors of a poor response were classical markers of disease severity including baseline D-dimer and LDH. Conversely, lymphopenia and lymphocyte*neutrophil product were associated with a better outcome, possibly as markers of a purer COVID-19 phenotype, uncomplicated by emergent bacterial infection. Alternatively, the responders may have been in an earlier phase of the disease, prior to progression from IL-6 mediated inflammation to a multi-cytokine dysregulated state, akin to HLH or MAS.

Although patients in both the ward based and ICU patient groups appeared to have a favourable response, the universal positive outcome in the ward based group, who all had evidence of hyperinflammation and severe respiratory compromise, might suggest that this treatment should be instituted as early as possible in patients with a hyperinflammatory phenotype. We advocated for and are pleased that the RECOVERY trial (ISRCTN50189673), ${ }^{29}$ one of the currently recruiting adaptive clinical trials of COVID-19 therapy has introduced a tocilizumab randomisation option in pre-ICU patients.

The importance of sharing information about COVID-19 is not only signalled by its recognition as a public health emergency of international concern (PHEIC), but also that it has become a notifiable disease in the UK. A public health imperative in these circumstances is to share information regarding the disease (with due regard to patient anonymity) with clinicians managing patients. Compassionate use of a drug is not considered to be research. We were careful to ensure that compassionate access of tocilizumab did not divert patients away from any existing clinical trials, to use conventional doses of tocilizumab so that results might be comparable to those used by others, and to adhere to Monitored Emergency Use of Unregistered and Investigational Interventions (MEURI) principles of WHO. We also secured extra supplies of tocilizumab so that patients being treated according to accepted indications would not risk their supply.

Compassionate use tocilizumab administered to patients with severe COVID-19 disease was associated with a rapid reduction in inflammation in all patients, accompanied by an improvement in 
oxygenation and better than expected clinical outcomes in nine of eleven patients. Although compassionate use treatment series are uncontrolled and cannot prove efficacy, if well conducted with detailed reporting of clinical parameters, they can contribute useful information in the drug development process. Our rapid evaluation of compassionate use tocilizumab for severe COVID-19 disease, shared in a timely manner as recommended by the World Health Organisation, can contribute useful information to the design and delivery of randomised controlled trials and large real world observational datasets of tocilizumab that are now underway. We are now actively enrolling participants in both national trials that include tocilizumab: the RECOVERY trial (ISRCTN50189673), ${ }^{29}$ with the addition of tocilizumab starting 23rd April, and the REMAP-CAP trial (NCT02735707), ${ }^{30}$ initiated at our hospital on 22nd April. It is hoped that accumulating patient data will allow for the stratification of the grade and severity of hyperinflammation and CRS which will then guide optimal timing and frequency of tocilizumab or other immunomodulatory therapies. We are encouraged by the improvement in clinical and laboratory abnormalities we carefully describe in this small series.

Author contributions

All authors meet all four of the designated criteria for authorship in the ICMJE recommendations. All authors contributed to the literature search, design, data analysis, interpretation, writing and review of the manuscript.

Declaration of interests

Susannah Leaver has provided consultancy to Roche. The other authors declare no conflicts of interest.

There was no specific funding for this case series and approval from an Ethics Committee was not required. 
References

1. Spychalski P, Blazynska-Spychalska A, Kobiela J. Estimating case fatality rates of COVID-19. Lancet Infect Dis 2020. doi: 10.1016/S1473-3099(20)30246-2.

2. Arentz M, Yim E, Klaff L, et al. Characteristics and Outcomes of 21 Critically III Patients With COVID-19 in Washington State. JAMA 2020. doi: 10.1001/jama.2020.4326.

3. Richardson S, Hirsch JS, Narasimhan M, et al. Presenting Characteristics, Comorbidities, and Outcomes Among 5700 Patients Hospitalized With COVID-19 in the New York City Area. JAMA 2020. doi: 10.1001/jama.2020.6775.

4. Intensive Care National Audit and Research Centre. https://www.icnarc.org/OurAudit/Audits/Cmp/Reports, accessed 24.04.2020

5. Ruan $Q$, Yang K, Wang W, Jiang L, Song J. Clinical predictors of mortality due to COVID-19 based on an analysis of data of 150 patients from Wuhan, China. Intensive Care Med 2020. doi: 10.1007/s00134-020-05991-x.

6. Zhou F, Yu T, Du R, et al. Clinical course and risk factors for mortality of adult inpatients with COVID-19 in Wuhan, China: a retrospective cohort study. Lancet 2020; 395(10229): 1054-62.

7. Mehta P, McAuley DF, Brown M, et al. COVID-19: consider cytokine storm syndromes and immunosuppression. Lancet 2020; 395(10229): 1033-4.

8. Qin C, Zhou L, Hu Z, et al. Dysregulation of immune response in patients with COVID-19 in Wuhan, China. Clinical infectious diseases : an official publication of the Infectious Diseases Society of America 2020. doi: 10.1093/cid/ciaa248

9. Giamarellos-Bourboulis EJ, Netea MG, Rovina N, et al. Complex Immune Dysregulation in COVID-19 Patients with Severe Respiratory Failure. Cell Host Microbe 2020. doi: 10.1016/j.chom.2020.04.009.

10. Maude SL, Laetsch TW, Buechner J, et al. Tisagenlecleucel in Children and Young Adults with B-Cell Lymphoblastic Leukemia. N Engl J Med 2018; 378(5): 439-48.

11. Kotch C, Barrett D, Teachey DT. Tocilizumab for the treatment of chimeric antigen receptor T cell-induced cytokine release syndrome. Expert Rev Clin Immunol 2019; 15(8): 813-22.

12. European Medicines

Agency.

https://www.ema.europa.eu/en/medicines/human/EPAR/roactemra, accessed 24.04.2020

13. Zhang $\mathrm{X}$, Song $\mathrm{K}$, Tong $\mathrm{F}$, et al. First case of COVID-19 in a patient with multiple myeloma successfully treated with tocilizumab. Blood Adv 2020; 4(7): 1307-10.

14. Luo P, Liu Y, Qiu L, Liu X, Liu D, Li J. Tocilizumab treatment in COVID-19: A single center experience. J Med Virol 2020. doi: 2020;10.1002/jmv.25801. 
15. Xu X, Han M, Li, T, et al. Effective Treatment of Severe COVID-19 Patients with Tocilizumab. 2020. http://www.chinaxiv.org/abs/202003.00026v1, access 24.04.2020.

16. WHO. Off-label use of medicines for COVID-19. https://www.who.int/newsroom/commentaries/detail/off-label-use-of-medicines-for-covid-19, accessed 24.04.2020.

17. Rockwood K, Song X, MacKnight $C$, et al. A global clinical measure of fitness and frailty in elderly people. CMAJ 2005; 173(5): 489-95.

18. Charlson ME, Pompei P, Ales KL, MacKenzie CR. A new method of classifying prognostic comorbidity in longitudinal studies: development and validation. J Chronic Dis 1987; 40(5): 373-83.

19. World Health Organisation. https://www.who.int/blueprint/priority-diseases/keyaction/COVID-19 Treatment Trial Design Master Protocol synopsis Final 18022020.pdf, accessed 20.04.2020

20. Pepys MB, Hirschfield GM. C-reactive protein: a critical update. J Clin Invest 2003; 111(12): 1805-12.

21. Worwood M. Indicators of the iron status of populations: ferritin. https://www.who.int/nutrition/publications/micronutrients/anaemia iron deficiency/97892415961 07 annex2.pdf, accessed 20.04.2020.

22. Mathilde Roumier RP, Matthieu Groh, Alexandre Vallee, Felix Ackermann. Interleukin-6 blockade for severe COVID-19. https://doi.org/10.1101/2020.04.20.20061861, accessed 24.04.2020

23. Lang VR, Englbrecht $M$, Rech J, et al. Risk of infections in rheumatoid arthritis patients treated with tocilizumab. Rheumatology (Oxford) 2012; 51(5): 852-7.

24. Rutherford Al, Subesinghe S, Hyrich KL, Galloway JB. Serious infection across biologic-treated patients with rheumatoid arthritis: results from the British Society for Rheumatology Biologics Register for Rheumatoid Arthritis. Ann Rheum Dis 2018; 77(6): 905-10.

25. Nishimoto N, Terao K, Mima T, Nakahara H, Takagi N, Kakehi T. Mechanisms and pathologic significances in increase in serum interleukin-6 (IL-6) and soluble IL-6 receptor after administration of an anti-IL-6 receptor antibody, tocilizumab, in patients with rheumatoid arthritis and Castleman disease. Blood 2008; 112(10): 3959-64.

26. Brudno JN, Kochenderfer JN. Toxicities of chimeric antigen receptor T cells: recognition and management. Blood 2016; 127(26): 3321-30.

27. Woo Y-L, Kamarulzaman A, Augustin Y, Staines H, Altice F, Krishna S. A genetic predisposition for Cytokine Storm in life-threatening COVID-19 infection. 2020. doi: 2020;10.31219/osf.io/mxsvw.

28. Delanghe JR, Speeckaert MM, De Buyzere ML. The host's angiotensin-converting enzyme polymorphism may explain epidemiological findings in COVID-19 infections. Clin Chim Acta 2020; 505: 192-3. 
29. The RECOVERY trial. https://www.recoverytrial.net/, accessed 24.04.2020.

30. REMAP-CAP trial. https://www.remapcap.org/, accessed 24.04.2020. 
Table 1. Characteristics of patients on day of tocilizumab prescription

\begin{tabular}{|c|c|c|c|}
\hline & All patients & $\begin{array}{ll}\text { Intubated } & \text { on } \\
\text { intensive care } & \end{array}$ & $\begin{array}{l}\text { Receiving high flow } \\
\text { oxygen on medical } \\
\text { ward }\end{array}$ \\
\hline Number & 11 & 7 & 4 \\
\hline Age (years) & $\begin{array}{l}56 \pm 11 \\
\text { (range 42-77) }\end{array}$ & $\begin{array}{l}52 \pm 9 \\
\text { (range 42-70) }\end{array}$ & $\begin{array}{l}62 \pm 13 \\
\text { (range 49-77) }\end{array}$ \\
\hline Sex (male, female) & 7,4 & 4,3 & 3,1 \\
\hline Clinical frailty score & $\begin{array}{l}1 \cdot 6 \pm 0 \cdot 8 \\
\text { (range 1-3) }\end{array}$ & $\begin{array}{l}1 \cdot 6 \pm 0 \cdot 8 \\
\text { (range 1-3) }\end{array}$ & $\begin{array}{l}1 \cdot 8 \pm 1 \cdot 0 \\
\text { (range 1-3) }\end{array}$ \\
\hline $\begin{array}{l}\text { Age-adjusted Charlson } \\
\text { Index }\end{array}$ & $\begin{array}{l}1 \cdot 4 \pm 1 \cdot 3 \\
\text { (range } 0-4 \text { ) }\end{array}$ & $\begin{array}{l}1 \cdot 0 \pm 1 \cdot 2 \\
\text { (range } 0-3 \text { ) }\end{array}$ & $\begin{array}{l}2 \cdot 0 \pm 1 \cdot 4 \\
\text { (range 1-4) }\end{array}$ \\
\hline $\begin{array}{l}\text { WHO ordinal scale at } \\
\text { referral }\end{array}$ & $\begin{array}{l}5 \cdot 4 \pm 1 \cdot 1 \\
\text { (range 4-7) }\end{array}$ & $\begin{array}{l}6 \cdot 1 \pm 0 \cdot 4 \\
\text { (range 6-7) }\end{array}$ & $\begin{array}{l}4 \cdot 0 \pm 0 \cdot 0 \\
\text { (range } 4-4)\end{array}$ \\
\hline $\begin{array}{l}\text { Symptom onset to } \\
\text { admission (days) }\end{array}$ & $8 \cdot 9 \pm 3 \cdot 1$ & $9 \cdot 7 \pm 3 \cdot 7$ & $7 \cdot 8 \pm 1 \cdot 5$ \\
\hline $\begin{array}{l}\text { Symptom onset to } \\
\text { tocilizumab (days) }\end{array}$ & $11 \cdot 7 \pm 4 \cdot 3$ & $11 \cdot 7 \pm 5 \cdot 1$ & $11 \cdot 8 \pm 3 \cdot 3$ \\
\hline $\begin{array}{lll}\text { Pneumonia } & \text { severity on } \\
\text { chest X-Ray } & & \\
\text { Mild } & \\
\text { Moderate } & \\
\text { Severe } & & \end{array}$ & $\begin{array}{l}1 \\
7 \\
3\end{array}$ & $\begin{array}{l}1 \\
3 \\
3\end{array}$ & $\begin{array}{l}0 \\
4 \\
0\end{array}$ \\
\hline $\begin{array}{l}\text { Oxygen requirement } \\
\text { Maximum } \mathrm{FiO} 2(\%) \\
\mathrm{P}: \mathrm{F} \text { ratio } \\
\text { Maximum flow rate }(\mathrm{L} / \mathrm{min})\end{array}$ & & $\begin{array}{l}64 \pm 12 \\
19 \cdot 1 \pm 4 \cdot 8\end{array}$ & $14 \cdot 5 \pm 1 \cdot 0$ \\
\hline Maximum temperature $\left({ }^{\circ} \mathrm{C}\right)$ & $38 \cdot 0 \pm 0 \cdot 9$ & $37 \cdot 8 \pm 1 \cdot 2$ & $38 \cdot 4 \pm 1 \cdot 0$ \\
\hline $\begin{array}{l}\text { Inflammation } \\
\text { CRP (mg/L) } \\
\text { D dimer (ng/L) } \\
\text { Ferritin (mcg/L) } \\
\text { LDH (IU/L) }\end{array}$ & $\begin{array}{l}311(138-332) \\
780(472-6000) \\
1073(900-4266) \\
530(381-775)\end{array}$ & $\begin{array}{l}188(136-326) \\
828(715-6000) \\
1500(1059-4825) \\
702(481-887)\end{array}$ & $\begin{array}{l}332(186-439) \\
413(344-4618) \\
785(332-1669) \\
397(366-496)\end{array}$ \\
\hline $\begin{array}{l}\text { Haematology } \\
\text { Lymphocytes (x10\%/L) }\end{array}$ & $\begin{array}{l}0.8 \pm 0.4 \\
\text { (range } 0.5 \text { to } 1.6 \text { ) }\end{array}$ & $\begin{array}{l}0.9 \pm 0.4 \\
\text { (range } 0.5 \text { to } 1.6 \text { ) }\end{array}$ & $\begin{array}{l}0.7 \pm 0.1 \\
\text { (range } 0.6 \text { to } 0.7 \text { ) }\end{array}$ \\
\hline Neutrophils $\left(\times 10^{9} / \mathrm{L}\right)$ & $\begin{array}{l}8 \cdot 0 \pm 2 \cdot 6 \\
\text { (range } 3 \cdot 8 \text { to } 11 \cdot 5 \text { ) }\end{array}$ & $\begin{array}{l}8 \cdot 0 \pm 2 \cdot 5 \\
\text { (range } 4 \cdot 1 \text { to } 10 \cdot 1 \text { ) }\end{array}$ & $\begin{array}{l}8 \cdot 1 \pm 3 \cdot 3 \\
\text { (range } 3 \cdot 8 \text { to } 11 \cdot 5 \text { ) }\end{array}$ \\
\hline Lymphocyte*neutrophil & $\begin{array}{l}7 \cdot 1 \pm 4 \cdot 5 \\
\text { (range } 2 \cdot 6 \text { to } 16 \cdot 0 \text { ) }\end{array}$ & $\begin{array}{l}8 \cdot 1 \pm 5 \cdot 2 \\
\text { (range } 2 \cdot 5 \text { to } 16 \cdot 0)\end{array}$ & $\begin{array}{l}5 \cdot 2 \pm 2 \cdot 3 \\
\text { (range } 2 \cdot 7 \text { to } 8 \cdot 1 \text { ) }\end{array}$ \\
\hline
\end{tabular}

Continuous variables are reported as mean \pm standard deviation, (range min to max) or median (interquartile range) 
Table 2. Percentage change in inflammatory markers and haematological parameters from baseline at different time points after tocilizumab treatment

\begin{tabular}{|c|c|c|c|c|}
\hline & \multicolumn{4}{|c|}{ Time from tocilizumab dose } \\
\hline & Day 1 post dose & Day 2 post dose & Day 3 post dose & $\begin{array}{l}1 \text { week post } \\
\text { dose }\end{array}$ \\
\hline C-reactive protein & $\begin{array}{l}+0 \cdot 9 \\
{[-34 \text { to }+35]}\end{array}$ & $\begin{array}{l}-48 \\
{[-67 \text { to }-30]}\end{array}$ & $\begin{array}{l}-76 \\
{[-85 \text { to }-68]}\end{array}$ & $\begin{array}{l}-85 \\
{[-106 \text { to }-64]}\end{array}$ \\
\hline Ferritin & $\begin{array}{l}+2 \cdot 3 \\
{[-15 \text { to }+20]}\end{array}$ & $\begin{array}{l}+1 \cdot 6 \\
{[-16 \text { to }+19]}\end{array}$ & $\begin{array}{l}-14 \\
{[-37 \text { to }+8]}\end{array}$ & $\begin{array}{l}-44 \\
{[-62 \text { to }-27]}\end{array}$ \\
\hline $\begin{array}{l}\text { Lactate } \\
\text { dehydrogenase }\end{array}$ & $\begin{array}{l}-6 \\
{[-18 \text { to }+6]}\end{array}$ & $\begin{array}{l}0 \\
{[-36 \text { to }+36]}\end{array}$ & $\begin{array}{l}+2 \\
{[-19 \text { to }+22]}\end{array}$ & $\begin{array}{l}-15 \\
{[-35 \text { to }+5]}\end{array}$ \\
\hline D-dimers & $\begin{array}{l}-4 \\
{[-22 \text { to }+14]}\end{array}$ & $\begin{array}{l}+95 \\
{[-64 \text { to }+254]}\end{array}$ & $\begin{array}{l}+176 \\
{[-37 \text { to }+389]}\end{array}$ & $\begin{array}{l}+183 \\
{[-55 \text { to }+420]}\end{array}$ \\
\hline Lymphocytes & $\begin{array}{l}+12 \\
{[-13 \text { to }+36]}\end{array}$ & $\begin{array}{l}-4 \\
{[-24 \text { to }+16]}\end{array}$ & $\begin{array}{l}+32 \\
{[-7 \text { to }+71]}\end{array}$ & $\begin{array}{l}+114 \\
{[+31 \text { to }+197]}\end{array}$ \\
\hline Neutrophils & $\begin{array}{l}-34 \\
{[-54 \text { to }-15]}\end{array}$ & $\begin{array}{l}-43 \\
{[-65 \text { to }-21]}\end{array}$ & $\begin{array}{l}-31 \\
{[-62 \text { to } 0]}\end{array}$ & $\begin{array}{l}-6 \\
{[-36 \text { to }+25]}\end{array}$ \\
\hline
\end{tabular}

Values are mean difference [95\% confidence interval of the difference] 
Table 3. Pre-tocilizumab characteristics of improvers and non-improvers

\begin{tabular}{|c|c|c|c|c|}
\hline & Improvers & \multicolumn{2}{|c|}{ Non-improvers } & P value \\
\hline Number & 9 & \multicolumn{2}{|l|}{2} & \\
\hline Age (years) & $55 \pm 11$ & 49 & 70 & 0.582 \\
\hline $\begin{array}{l}\text { Symptom onset to } \\
\text { tocilizumab (days) }\end{array}$ & $12 \cdot 3 \pm 4 \cdot 5$ & & & $0 \cdot 400$ \\
\hline $\begin{array}{l}\text { Oxygen requirement } \\
\text { P:F ratio (ICU) } \\
\text { Maximum flow rate } \\
\text { (L/min) (ward) }\end{array}$ & $\begin{array}{l}20 \cdot 4 \pm 5 \cdot 1 \\
14 \cdot 5 \pm 1 \cdot 0\end{array}$ & 18 & 14 & $0 \cdot 381$ \\
\hline $\begin{array}{l}\text { Maximum } \\
\text { temperature }\left({ }^{\circ} \mathrm{C}\right)\end{array}$ & $38 \cdot 3 \pm 0 \cdot 9$ & $37 \cdot 9$ & $36 \cdot 5$ & $0 \cdot 218$ \\
\hline $\begin{array}{l}\text { Inflammation } \\
\text { CRP (mg/L) } \\
\text { D dimer (ng/L) } \\
\text { Ferritin (mcg/L) } \\
\text { LDH (IU/L) }\end{array}$ & $\begin{array}{l}326(157-354) \\
715(413-1712) \\
1073(779-3094) \\
465(366-629)\end{array}$ & $\begin{array}{l}125 \\
6000 \\
17005 \\
872\end{array}$ & $\begin{array}{l}188 \\
6000 \\
1059 \\
933\end{array}$ & $\begin{array}{l}0.218 \\
0 \cdot 073 \\
0.436 \\
0 \cdot 044\end{array}$ \\
\hline $\begin{array}{l}\text { Haematology } \\
\text { Lymphocytes (x109/L) } \\
\left.\text { Neutrophils ( } \times 10^{9} / \mathrm{L}\right) \\
\text { Lymphocyte* neutrophil }\end{array}$ & $\begin{array}{l}0 \cdot 7 \pm 0 \cdot 2 \\
7 \cdot 7 \pm 2 \cdot 8 \\
5 \cdot 5 \pm 3 \cdot 0\end{array}$ & $\begin{array}{l}1 \cdot 6 \\
10 \cdot 0 \\
16 \cdot 0\end{array}$ & $\begin{array}{l}1 \cdot 4 \\
8 \cdot 6 \\
12 \cdot 0\end{array}$ & $\begin{array}{l}0.036 \\
0.582 \\
0.036\end{array}$ \\
\hline
\end{tabular}

Values for improvers given as mean \pm standard deviation or median (interquartile range) and for non-improvers given as individual patient measurements. Group values for improvers and nonimprovers compared with a Mann-Whitney Test 


\section{Figure legends}

Figure 1. Change in inflammation after tocilizumab dosing

a) Maximum temperature and b) C-reactive protein are shown for 2 days before, on the day of tocilizumab dosing and for 7 days after. Lines represent values for individual patients; those represented by a grey line received one dose of tocilizumab and those represented by a black line received 2 doses. Survivors at the end of the follow up period are shown with a solid line and those who died with a dotted line. All patients requiring 2 doses also required new antibiotics after tocilizumab.

Figure 2. Oxygen requirements on the day of tocilizumab treatment and one week later

Oxygen requirements are shown for a) ward-based patients (mean oxygen flow rate (L/min) over 24 hours) and b) intensive care patients $\left(\mathrm{PaO}_{2}(\mathrm{kPa})\right.$ to $\mathrm{FiO}_{2}(\%)$ ratio) on the day of tocilizumab treatment and one week later. Lines represent values for individual patients; those represented by a grey line received one dose of tocilizumab and those represented by a black line both received 2 doses and required additional antibiotics. Survivors at the end of the follow up period are shown with a solid line and those who died with a dotted line. Letters identify individual patients for comparison with figure 3.

Figure 3. Daily scores on the WHO ordinal scale for clinical improvement on day of tocilizumab treatment to discharge, death or latest follow up day

Lines represent values for individual patients; those represented by a grey line received one dose of tocilizumab and those represented by a black line both received 2 doses and required additional antibiotics. Survivors at the end of the follow up period are shown with a solid line and those who died with a dotted line. Letters identify individual patients for comparison with figure 2 . 
Figure 1

a)

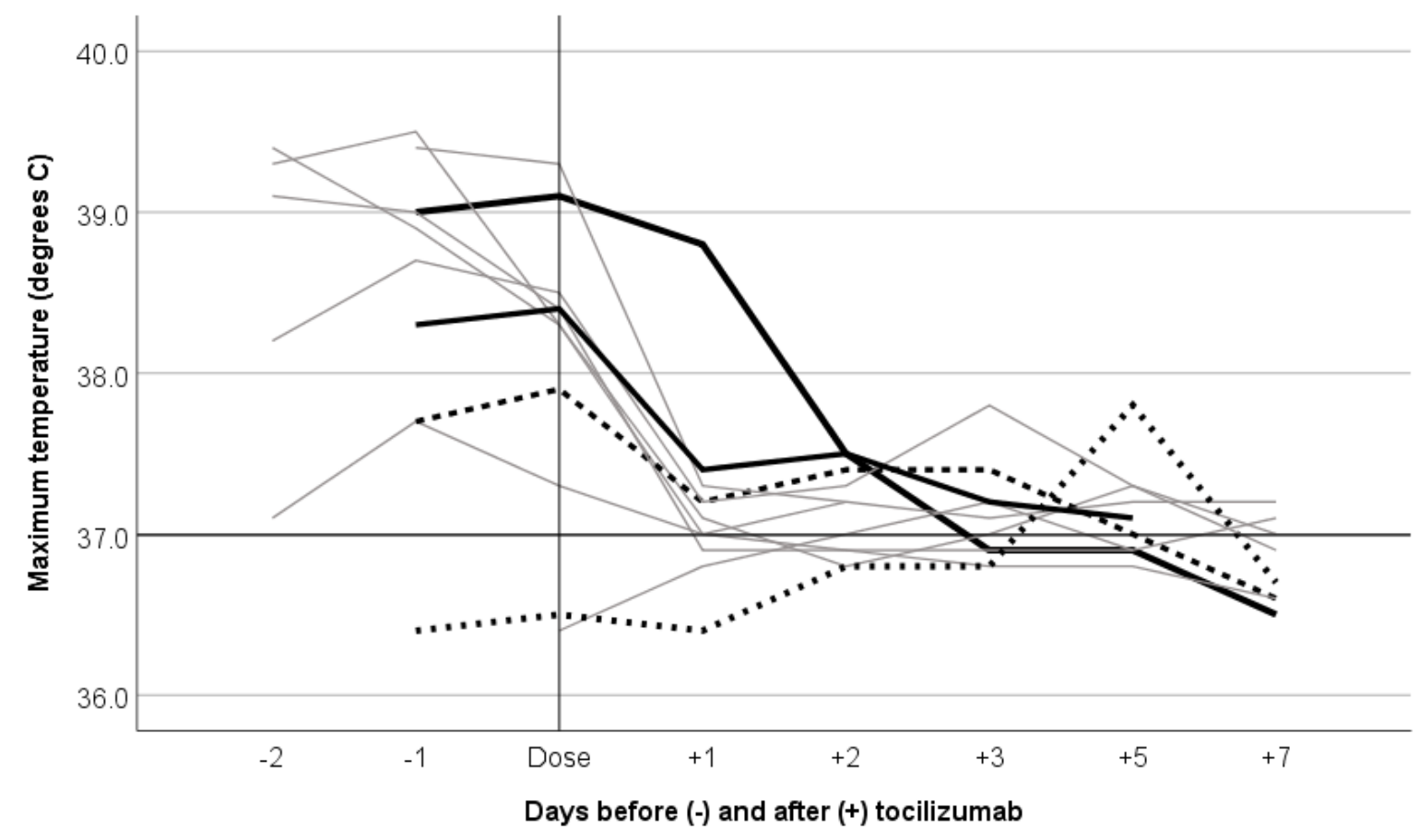

b)

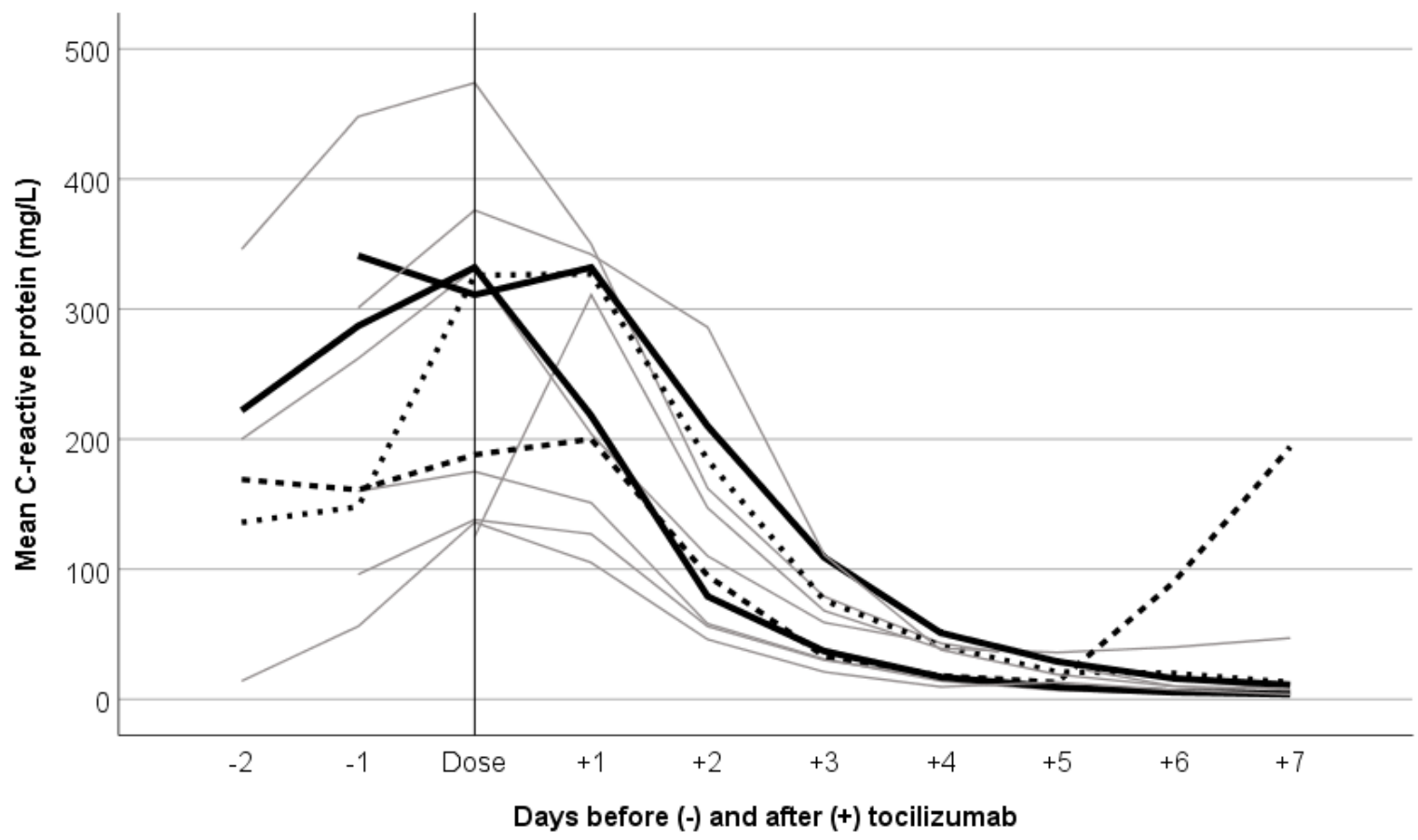


Figure 2

a)

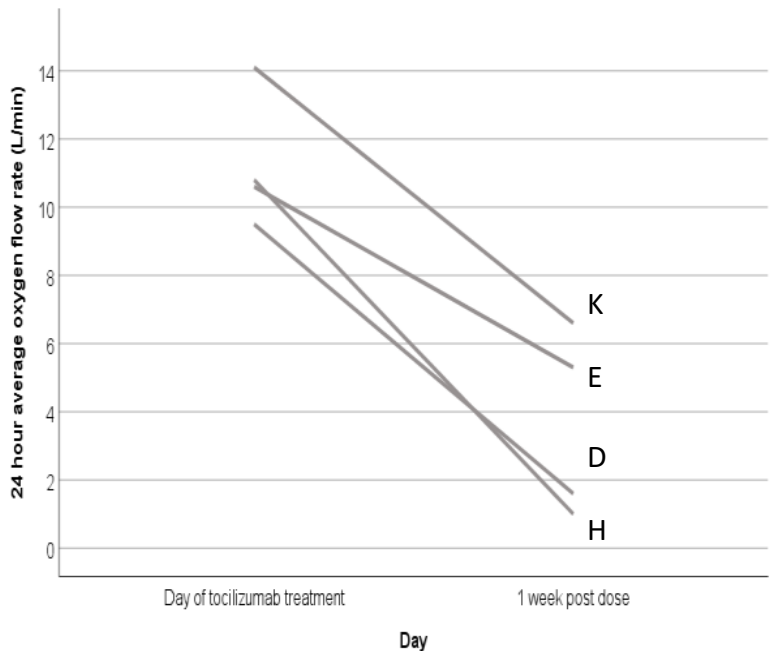

b)

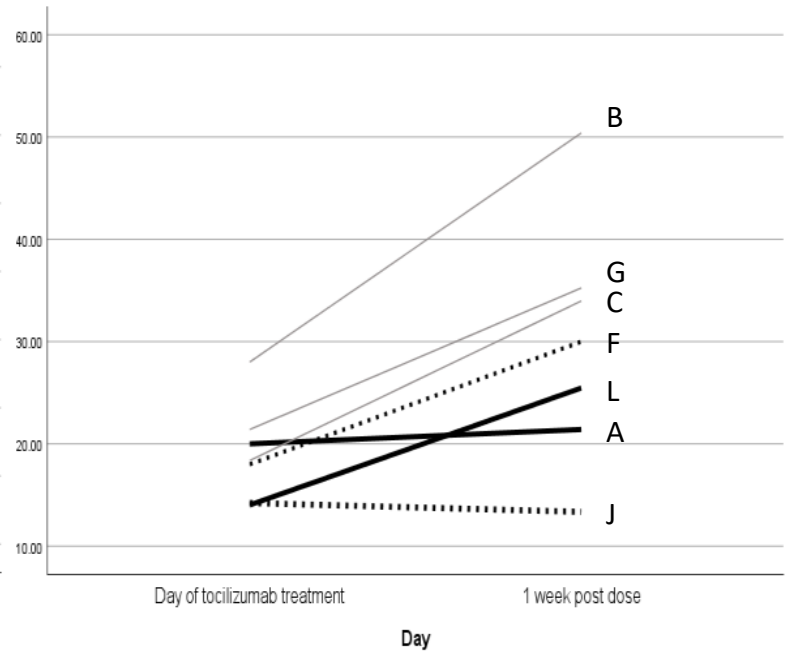


Figure 3

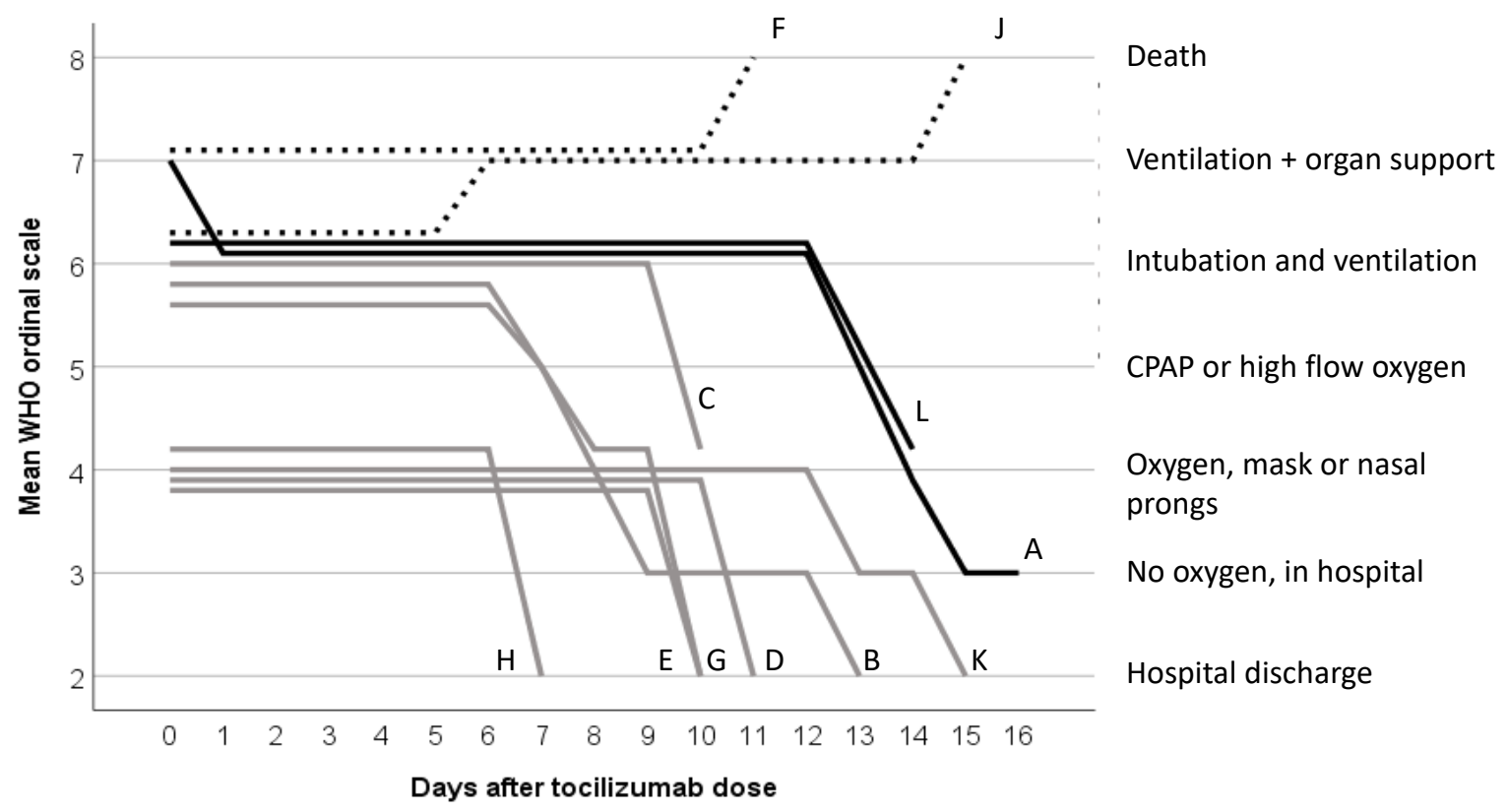




\section{Supplementary 1}

\section{Compassionate use of Tocilizumab for Severe COVID-19 - Guidance for Clinicians}

\section{Inclusion criteria:}

- Confirmed SARS-Coronavirus-2 by PCR

- CXR (or CT Chest) confirming bilateral infiltrates

- Evidence of a hyper-inflammation phenotype

Subset of patients:

- Intubated patients within 24 hours (extended to 48 hours for external referrals direct to ITU)

or

- Fever $\left(>37.8^{\circ} \mathrm{C}\right)$ and inspired oxygen requirements of $\geq 28 \%$

Hyper-inflammation marker panel supporting hyper-inflammation phenotype:

- D-dimer $>U L N$

- CRP rising

- Ferritin $>1000 \mathrm{ng} / \mathrm{ml}$

- $\mathrm{LDH}>\mathrm{ULN}$

\section{Exclusion criteria:}

Three abnormal parameters support

hyper-inflammation phenotype

- ALT or AST >10 times the upper limit of normal.

- Evidence of synthetic liver failure

- Neutrophils $<0.5 \times 10^{9} / \mathrm{L}$

- Platelets $<50 \times 10^{9} / \mathrm{L}$

- Pre-existing diverticulitis or risk of intestinal perforation

- Known hypersensitivity to tocilizumab

- Multi-organ failure

- Bacterial sepsis (clinical judgement supported by high neutrophils, normal lymphocytes)

- Clinical frailty score $>6$

- Charlson comorbidity index $>6$

These groups of patients are further characterised in Figure 1. Treatment can commence if three clinicians from a constituted MDT agree it is appropriate (members of the panel and frontline clinicians with appropriate experience to make this decision)

Documentation of consent process:

Eligible patients will be offered this treatment option with a full explanation of potential benefits and potential risks (of no benefit or small risk of adverse events). If the patient is unwell or unconscious, this discussion will occur with the patient's representative or next of kin, where possible. If it is not possible to obtain consent from a patient because of respiratory distress or intubation, it is appropriate to commence treatment based on best interest with full documentation. Dosing:

- Tocilizumab i.v. $8 \mathrm{mg} / \mathrm{kg}$ up to a maximum of $800 \mathrm{mg}$ per diluted in $100 \mathrm{ml} 0.9 \%$ Normal Saline given over $1 \mathrm{hr}$

- A second dose can be administered any time after $12-48$ hours if respiratory function is not restored

\section{Safety checks}

- Hepatitis B serology (HBV core antibody, surface Ag) to be sent but results not required prior to commencing treatment 
Figure 1: Compassionate use of Tocilizumab for severe COVID-19 flow diagram

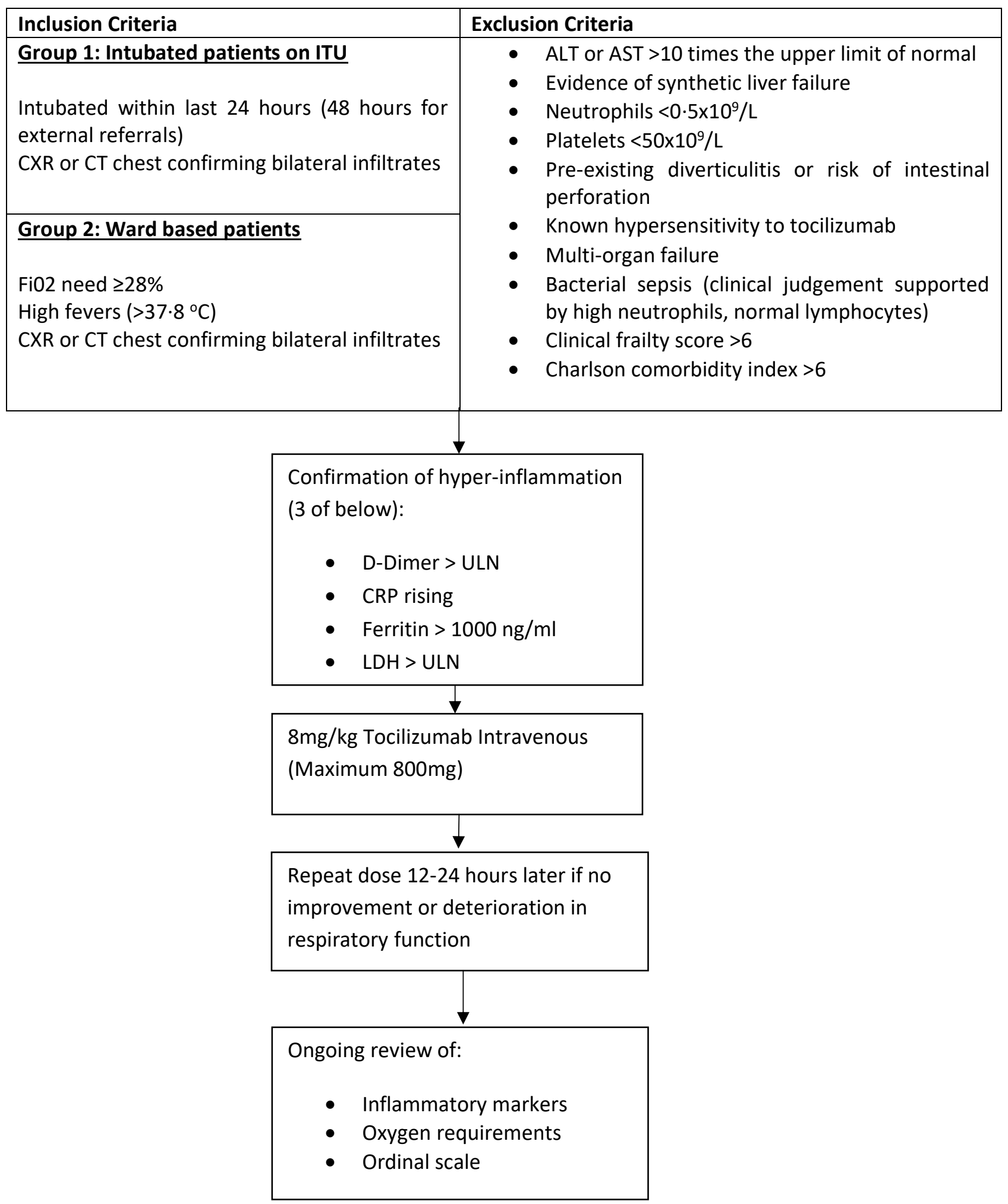

